University of Nebraska - Lincoln

DigitalCommons@University of Nebraska - Lincoln

Sociology Department, Faculty Publications

Sociology, Department of

$4-2006$

\title{
Explaining Disparities in Treatment Seeking: The Case of Infertility
}

Lynn K. White

University of Nebraska-Lincoln, Iwhite3@unl.edu

Julia McQuillan

University of Nebraska-Lincoln, jmcquillan2@Unl.edu

Arthur L. Greil

Alfred University, fgreil@alfred.edu

Follow this and additional works at: https://digitalcommons.unl.edu/sociologyfacpub

Part of the Sociology Commons

White, Lynn K.; McQuillan, Julia; and Greil, Arthur L., "Explaining Disparities in Treatment Seeking: The Case of Infertility" (2006). Sociology Department, Faculty Publications. 121.

https://digitalcommons.unl.edu/sociologyfacpub/121

This Article is brought to you for free and open access by the Sociology, Department of at DigitalCommons@University of Nebraska - Lincoln. It has been accepted for inclusion in Sociology Department, Faculty Publications by an authorized administrator of DigitalCommons@University of Nebraska - Lincoln. 
Published in Fertility and Sterility 85:4 (April 2006), pp. 853-857; doi 10.1016/j.fertnstert.2005.11.039.

Copyright () 2006 American Society for Reproductive Medicine; published by Elsevier. Used by permission.

Research for this article was supported by a grant from the National Institute of Child Health and Human Development (NICHD) (1 R01 HD044144-01). Presented at the NICHD conference, "Disparities in Infertility," Bethesda, Maryland, March 1011, 2005. Reprint requests: Lynn White, Ph.D., Department of Sociology, University of Nebraska-Lincoln, Lincoln, NE 68588-0324 (fax 402-472-6070; email: lwhite@unlnotes.unl.edu ).

Submitted May 16, 2005; revised and accepted November 30, 2005.

\title{
Explaining Disparities in Treatment Seeking: The Case of Infertility
}

\author{
Lynn White, Ph.D., ${ }^{*}$ Julia McQuillan, Ph.D., ${ }^{*}$ and Arthur L. Greil, Ph.D.† \\ * Department of Sociology, University of Nebraska-Lincoln \\ $\dagger$ Division of Social Sciences, Alfred University, Alfred, New York
}

Objective: To present an integrated model of help-seeking, review empirical work in its support, and show its application to the explanation of racial and ethnic disparities in infertility help-seeking.

Conclusions: A help-seeking model provides a plausible explanation of observed disparities in infertility help-seeking. In addition to being related to income, race and ethnicity is related to prior experience with doctors, marital status, parity, knowledge and attitudes toward reproductive technology, and attitudes supporting spiritual rather than technological solutions to health problems.

Medical science in the early twenty-first century has an impressive capacity to help people live longer and healthier lives, but some of this capacity is unused because people do not seek medical help, do not seek help promptly, or do not complete recommended treatments. This helpseeking gap exists for life-threatening conditions, such as heart disease and cancer, and also for quality-of-life conditions, such as incontinence and infertility. The help-seeking gap contributes to unnecessary morbidity and mortality and is widely regarded as one cause of observed racial and social class disparities in health and mortality (1). As a result, a substantial body of work has developed to explain the process of help-seeking across medical conditions.

Help-seeking theories focus on the individual patient's decision to seek help, but they do not blame lack of treatment solely on the individual. Rather, such theories place help-seeking efforts in a broad framework that includes structural inequalities in income and health insurance, stereotyping and bias among medical professionals, cultural and communication barriers, as well as the individual's own social networks, attitudes, and circumstances, all of which might influence the likelihood that an individual can and will pursue treatment. Thus, understanding help-seeking pathways should be an important part of the national effort to confront racial and ethnic disparities in health care $(1,2)$, including disparities in infertility treatment. Our goal in this article is to integrate help- seeking theories, assess the evidence in support of them, and apply them to the case of infertility. Where possible, we illustrate these ideas from a pilot study of infertility help-seeking.

\section{An Integrated Model for Understanding Pathways to Treatment}

Our goal is to understand the pathways that lead toward or away from treatment for infertility. In doing so, we draw from general models of help-seeking developed by Andersen (1968) (2), Becker (1974) (3), Pescosolido and Boyer (1998) (4), and Shaw (1999) (5). These theories were designed to explain well-documented patterns of disparities in treatment seeking across conditions as varied as heart disease, cancer, urinary incontinence, and mental illness. We first outline a general integrated theory and then discuss how it should explain observed disparities in treatment seeking for infertility.

\section{The Help-Seeking Process}

The central assumption for theories of help-seeking is that moving from symptoms to medical treatment is a complex process. Although any breakdown is somewhat arbitrary, a simple four-step process includes symptoms, perception of a problem, consideration of alternative responses, and behavioral responses. 
In the case of an acute heart attack, we might expect this whole process to take 1.5 minutes, whereby the symptom occurs, a knowledgeable person recognizes it, decides that the need for medical treatment is urgent, and calls 911. Even in this case, however, research shows that people waste considerable time wondering whether it is heartburn and waiting to see whether symptoms will go away (6). In less acute

cases, someone might spend weeks or months of uncertainty before concluding that their symptoms really constitute a problem, then another period of months dosing themselves with over-the-counter remedies and talking to their friends before they decide to seek formal medical treatment (7).

Few symptoms for any condition, especially in the early stages, demand urgent medical attention, and individuals and societies engage in processes of social definition that seek to identify the urgency, severity, and source of symptoms (8). Across conditions from HIV to ovarian cancer, misattribution of symptoms is a significant cause of delays in help-seeking $(9,10)$.

In the case of infertility, the symptom is failure to conceive after a number of months of unprotected intercourse. Because infertility is heralded not by the development of new and undesired symptoms but by the absence of change, perception of a problem is particularly problematic. Conception failure might be attributed to stress, mistiming of intercourse, aging, or normal variation. Our pilot study confirms that recognizing that one has fertility problems is the single most important predictor of helpseeking (11).

Once fertility is perceived as a problem, alternative solutions need to be assessed. These considerations include the need for treatment (i.e., how likely it is that the situation will resolve itself), perception of options (childlessness, medical help, self-care, and adoption), and perception of the benefits of and barriers attached to various options. This "cognitive processing" (5) is critical in all theories of help-seeking. Unless symptoms are so severe (e.g., a public collapse) that others deliver you to treatment providers, treatment seeking requires an active decision to pursue treatment and, in many cases, a substantial degree of determination to identify an appropriate provider and persist until treatment is provided.

In thinking about help-seeking for infertility, as for any medical condition, it is important to recognize that professional medical treatment seeking is only one of the possible behavioral responses. Indeed, for almost all conditions, some sort of self-care precedes professional treatment seeking (12). Others might pursue religious or alternative medical solutions instead of or in addition to medical help-seeking.

\section{Determinants of Help-Seeking}

To understand disparities in help-seeking, we need to examine the circumstances that predispose people to perceive a problem, decide that medical help is an appropriate response, and actually seek help. Integrating ideas from a variety of help-seeking theories, we group major explanatory concepts in the categories of social, individual, and temporal cues, enabling conditions, and predisposing conditions. Background variables, including race and ethnicity and socioeconomic status, are expected to work through these explanatory variables.

We preface this review by noting that theorizing about help-seeking has outpaced research. We cite a patchwork of empirical studies that assesses the effect of one or two factors on a specific medical condition. Because treatment-seeking processes might very well differ depending on whether the outcome is cancer, HIV, or incontinence, the support that these studies offer for theory must be regarded as tentative. There is even less research on helpseeking processes for infertility itself. Most research on infertility has been confined to clinic populations, by definition help-seekers, with the result that it sheds little light on who is most apt to seek help.

Social Cues. Help-seeking theorists hypothesize that perceiving the absence of conception as a signal of infertility, reaching a positive judgment about the need for, availability of, and efficacy of medical treatment, and actually seeking treatment depend in part on social cues. These include perceived approval for infertility treatment, perceived pressure for children from partners, parents, and community, perceived stigma of infertility, and the experiences and support of friends and family.

A study of women's help-seeking decisions regarding hysterectomy demonstrates that most women rely on the advice of friends and family and have already decided on appropriate treatment before consulting a doctor (13). Support from others has been found to be a strong predictor of treatment seeking for urinary tract infections (14), mental health problems (15), brain tumors (16), and infertility (17). On the other hand, perceived stigma has been shown to delay treatment seeking for incontinence (18) and HIV (19) and has also been implicated in infertility (20).

Individual Cues. Individual attitudes and circumstances affect the help-seeking process. Generally, the more severe the impact of the condition on daily life, the more likely people are to seek care (21). In the case of infertility, we suggest that the severity of impact might be measured by strength and immediacy of fertility plans, whether one already has children, and the salience of a parent identity. A survey in Malawi confirms that a high ideal number of children is associated with infertility treatment-seeking (22). Thus, we would expect that those who intend children, who feel a sense of urgency about having them, who have had no prior children, and who cannot imagine their lives without children (or without children of a particular gender) are most apt to move quickly to medical help-seeking.

Research on breast cancer and HIV suggests that those who are most distressed about the possibility of cancer are slowest to seek help $(19,23)$. Applied to infertility, this suggests that those for whom a diagnosis of infertility would be most threatening might delay a visit that might confirm 
their worst fears. On the other hand, some research suggests that those who are especially anxious might over-use medical services (24), for example, seeing their physician after only 2 or 3 months of unprotected intercourse.

Life Course Cues. Pescosolido (25) has emphasized the need to consider the social contexts in which health decisions are made and the dynamic nature of treatmentseeking trajectories. An unmarried 18-year-old who does not get pregnant after 1 year of unprotected intercourse is more likely to say "thank God" than seek medical attention. Help-seeking is more likely when life course cuesespecially age, marriage, and education completionmake childbearing normative and desirable. Thus, we anticipate, faced with the same objective symptoms, that older and married women who have completed their educations are more likely to seek medical help for fertility impairment.

Enabling Conditions. A major chasm might exist between wanting help and getting help. Theories of help-seeking group the resources that make it possible to get desired help under the rubric of "enabling conditions." Financial resources, including income and health insurance, are most important (26-28), but resources such as education and social support have also been shown to increase the propensity to seek treatment (29).

Predisposing Conditions. Across a wide variety of medical conditions, empirical research has identified a set of conditions that predispose individuals to seek medical help independent of symptom severity. These include comorbidity, having a usual doctor, and health attitudes and beliefs (including knowledge of specific symptoms and their treatment, medical anxiety, and medical locus of control). The importance of each of these elements is supported by scattered empirical research across an array of symptoms.

Those who have a usual doctor and who trust their doctor are more likely to seek medical help than those who use emergency rooms for routine care, who wait at public health clinics, who have to identify a doctor before seeking treatment, or who distrust their doctor (30). In the case of infertility, a regular doctor is more likely to be aware of signs of fertility impairment and raise the issue with a patient who might be reluctant to identify herself as being infertile. Individuals who believe that biomedical solutions are effective are more likely to seek care than those who hold alternative views $(29,31,32)$, whereas those who are fearful of medical treatment are less likely to seek care generally (18). Specifically in the case of infertility, medical anxiety (33), pessimism about the results of treatment (34, 33) and high internal medical locus of control (11) have been found to deter treatment seeking.

Finally, those who have had positive prior experiences with medical institutions and their doctor are more likely to seek help than those who have experienced rude, uncaring, or ineffective care (36). We know that minorities have less trust of their doctors (37) and expect racism from their doctors (38). These beliefs have been supported by research establishing that doctors are significantly and substantially more likely to have a variety of negative stereotypes about African American than other patients (39).

\section{Summary}

Our goal is to provide an integrated conceptual model of help-seeking and to identify the chief variables hypothesized to explain movement from objective biomedical symptoms to actual help-seeking. The explanatory variables are hypothesized to affect help-seeking directly but also to moderate the intervening processes. For example, individuals with health insurance, a usual doctor, and a positive attitude toward medical treatment are likely to be quicker to identify symptoms as being a biomedical problem, more likely to reach a positive assessment of the cost/benefit ratio of treatment seeking, and quicker to move to professional medical care. On the other hand, unmarried women without health insurance or a regular doctor and whose partner does not want children might be slower to wonder whether this is a medical problem, more likely to decide that the costs of medical treatment outweigh the benefits, and more likely to consider nonmedical options.

\section{Explaining Disparities}

Data from the National Survey of Family Growth suggest that approximately half of women with infertility impairments do not seek treatment to resolve impaired infecundity (40) and that treatment seeking is linked to race and ethnicity and social class indicators. Because infertility treatment is expensive, it is tempting to conclude that financial availability of treatment is the key explanatory factor. This rationale is supported by the fact that nations with national health care systems report higher rates of infertility help-seeking than in the United States (e.g., 67\% in Finland, $86 \%$ in The Netherlands, and $72 \%-95 \%$ in the United Kingdom) (41). Studies in the United States show that income and health insurance are strong predictors of treatment seeking for fertility impairment (40). Because a growing number of states mandate that health insurance cover infertility treatment, overall rates of treatment seeking are likely to rise (42). Major racial disparities in health insurance coverage (11\% of non-Hispanic whites, $20 \%$ of African Americans, and 33\% of Hispanics are without health insurance coverage [43]) are just one reason that such laws are unlikely to reduce racial disparities in treatment seeking $(42,44)$.

Financial factors are undoubtedly important, yet research on a variety of other medical conditions makes it clear that disparities in health care and health outcome persist after adjustments for income and insurance. For example, African American Medicare beneficiaries are only half as likely as white beneficiaries to get free influenza vaccinations (45). Thus, although income and health insurance are important reasons for health disparities, much of the answer has to be found elsewhere. 
The framework we have just outlined suggests that it is also important to consider differentials in the likelihood of perceiving a problem, cognitive appraisals of the alternatives, or in predisposing conditions (e.g., medical anxiety and trust in medical professionals) and social and individual cues. For example, in addition to obvious structural barriers, such as income and health insurance, African American women's lower use of infertility treatment is probably attributable to factors such as cultural aversion to technological solutions to a holistic health problem, greater aversion to infertility labels and treatments, greater distrust of a medical establishment that has victimized minorities in the past $(37,38)$, bad experiences with their own doctors (46), or a belief that they will be rejected for treatment.

Such beliefs are often grounded in empirically confirmed reality. Recent research reports that one in five treatment providers refuses treatment to unmarried women (47). Because African American women are much less likely to be married than non-Hispanic white women (e.g., 69\% of white women aged 30-34 years were married in 2003, compared with only $37 \%$ of black women), some of the racial disparity must rest directly on gate-keeping by providers. For all of these reasons, Molock (1999) (48) suggests that childless African Americans are more apt than other groups to resolve infertility through formal or informal adoption and more likely to seek spiritual solutions.

With a multidisciplinary team, we are currently in the process of gathering data on a national sample of 5,500 women and approximately 2,000 partners, all of whom will be interviewed once in 2005 and again in 2008. This national panel should enable us to identify factors that lead women and couples to recognize and deal with their infertility.

In the meantime, we have explored some of the implications of this model, using pilot data from an institutional review board (IRB)-approved study of 196 midwestern women who had ever experienced fertility barriers (12). This analysis supports the importance of cognitive processes and of such variables as comorbidity and internal health locus of control. Both income and race and ethnicity are significantly related to help-seeking at the bivariate level. The effects of income are partly indirect, and the effects of race and ethnicity are largely indirect. Higher income and majority race and ethnic status are part of a set of individual and life course cues - being married, childless, and trying to conceive after 30 years of age - that are independently important to help-seeking. Together, these variables mean that couples are ready to have children and are monitoring conception. As a result, they are more likely to recognize signs of subfecundity and to seek help.

\section{Materials and Methods}

The conceptual framework for explaining health disparities in infertility is part of a larger National Institute of
Child Health and Development grant to study infertility pathways and outcomes. We obtained IRB approval for this larger project. None of the authors have a conflict of interest between the statements in this article and other work that they are doing.

\section{Discussion}

Seeking medical help for infertility is not a simple mechanical process. Unlike public health issues, such as tuberculosis, there is no social imperative that everyone seeks help. Unlike cancer or high blood pressure, there is no individual imperative to seek treatment to avoid pain or death. Infertility treatment is but one of many behavioral responses to infertility, and we must expect that a sizable minority who experience fertility impairment will not seek treatment at all or will seek only a diagnosis and no treatment. Of these, some will be so ambivalent or even negative about childbearing that they will accept infertility with equanimity. Others will swallow their disappointment without struggling for a medical solution, oftenjudging from our preliminary findings - accepting this as "God's will."

Our concern is with those women and men who want to have children but who do not know of, do not have access to, or do not trust the medical establishment enough to pursue appropriate and effective treatment. In this regard, we are likely to find that infertility disparities closely model disparities that exist in other health outcomes.

These disparities have recently been addressed in a National Academy report (2). The interventions recommended in that report (defragmentation of health care financing and delivery, strengthening doctor-patient relationships, incorporating patient protections, multidisciplinary teams, patient education and empowerment, accountability) will undoubtedly reduce disparities in infertility treatment as well.

We add a further consideration specific to fertility care. We suggest that race-based and class-based ideas (conscious and unconscious) about who deserves to be a mother shape potential patients' and care providers' assumptions about who should get treatment. Most obviously, these appear in clinic policies about whether, for example, unmarried women should receive treatment. We recommend that care providers explore their assumptions about who should be mothers and how those assumptions translate into practices. In sum, greater equality of outcomes requires not only reducing the economic barriers to treatment but also addressing broader disparities that shape experiences, expectations, knowledge, and trust.

\section{Acknowledgments}

The authors thank David R. Johnson, Ph.D., Laurie Scheuble, Ph.D., Mary Casey Jacob, Ph.D., and Naomi Lacy, Ph.D., members of the team that designed the larger study of which this is a part. 


\section{References}

1. Smedley BD, Stith AY, Nelson AR, eds. Unequal treatment: confronting racial and ethnic disparities in health care. Washington, DC: The National Academies Press, 2002.

2. Anderson R, A behavioral theory of families' use of health services. Chicago: University of Chicago Center for Health Administration Studies, 1968.

3. Becker MH. The health belief model and personal health behavior. San Francisco: Society for Public Health Education, 1974.

4. Pescosolido B, Boyer C. The utilization of mental health services: state of the art and changing perspectives. In: Horwitze AV, Scheid TL, eds. the sociology of mental health and illness. New York: Cambridge University Press, 1999.

5. Shaw C. A framework for the study of coping, illness behaviour and outcomes. J Adv Nursing 1999; 29:1246-55.

6. Rasmussn CH, Munck A, Krastrup J, Hagfelt T. Patient delay from onset of chest pain suggesting acute coronary syndrome to hospital admission. Scand Cardiovasc J 2003; 37:183-186.

7. Gannon K, Glover L, O'Neill M, Emberton M. Men and chronic illness: a qualitative study of LUTS. J Health Psychol 2004; 9:411-20.

8. Zola IK. Pathways to the doctor-from person to patient. Soc Sci Med 1973; 7:677-89.

9. Siegel K, Schrimshaw EW. Symptom interpretation: implications for delay in HIV testing and care among HIV-infected middle-aged and older adults. AIDS Care 1999; 11:525-35.

10. Yawn BP, Barrette BA, Wollan PC. Ovarian cancer: the neglected diagnosis. Mayo Clin Proc 2004; 79:1277-82.

11. White L, McQuillan J, Greil AL, Johnson DR. Infertility: testing a help-seeking model. Soc Sci Med 2006; 62:1031-41.

12. Schoenberg NE, Amey CH, Stoller EP, Drew EM. The pivotal role of cardiac self-care in treatment timing. Soc Sci Med 2005; 65:1047-60.

13. Uskul A, Ahmad F, Na L, Stewart D. Women's hysterectomy experiences and decision-making. Women Health 2003; 38:53-67.

14. Wolters R, Wensing M, Van Weel C, Van Der Wilt GJ, Grol RP. Lower urinary tract symptoms: social influence is more important than symptoms in seeking medical care. BJU Int 2002; 90:655-61.

15. Carpentier N, White D. Cohesion of the primary social network and sustained service use before the first psychiatric hospitalization. J Behav Health Services Res 2003; 29:404-18.

16. Salander P, Bergenheim A, Hamberg K, Henriksson R. Pathways from symptoms to medical care: a descriptive study of symptom development and obstacles to early diagnosis in brain tumour patients. Fam Pract 1999; 16:143-8.

17. Fortier C, Wright J, Sabourin S. Social support system and withdrawal from medically assisted reproduction programs at fertility clinics. Int J Psychol 1992; 27-33.

18. Margalith I, Gillon G, Gordon D. Urinary incontinence in women under 65: quality of life, stress related to incontinence and patterns of seeking health care. Qual Life Res 2004; 13:1381-90.

19. Raveis VH, Siegel K, Gorey E. Factors associated with HIV-infected women's delay in seeking medical care. AIDS Care 1998; 10:549-62.

20. Greil AL. A secret stigma: the analogy between infertility and chronic illness and disability. Adv Med Sociol 1991; 2:17-38.

21. Hannestad YS, Rortveit G, Hunskaar S. Help-seeking and associated factors in female urinary incontinence. The Norwegian EPINCONT Study. Scand J Prim Health Care 2002; 20:102-7.

22. Barden-O'Fallon J. Associates of self-reported fertility status and infertility treatment-seeking in a rural district of Malawi. Hum Reprod 2005; 20:2229-36.

23. Meechan G, Collins J, Petric KJ. The relationship of symptoms and psychological factors to delay in seeking medical care for breast symptoms. Prev Med 2003; 36:374-8.

24. McIntosh H. Few Native Americans journey into medical oncology. J Natl Cancer Inst 1996; 88:325-7.

25. Pescosolido B. Beyond rational choice: the social dynamics of how people seek help. Am J Sociol 1992; 97:1096-1138.

26. Burge MR, Lucero S, Rassam AG, Schade DS. What are the barriers to medical care for patients with newly diagnosed diabetes mellitus? Diabetes Obes Metab 2000; 2:351-4.
27. Diamant AL, Hays RD, Morales LS, Ford W, Calmes D, Asch S, et al. Delays and unmet need for health care among adult primary care patients in a restructured urban public health system. Am J Public Health 2004; 94:783-9.

28. Jovanovic Z, Lin CJ, Chang C-CH. Uninsured vs. insured population variations among nonelderly Americans. J Health Soc Policy 2003; 17:71-85.

29. deNooijer J, Lechner L, de Vries H. Social psychological correlates of paying attention to cancer symptoms and seeking medical help. Soc Sci Med 2003; 56:915-20.

30. O'Connor PJ, Desai J, Rush WA, Cherney LM, Solberg LI, Bishop DB. Is having a regular provider of diabetes care related to intensity of care and glycemic control? J Fam Pract 1998; 47:290-7.

31. Hunter MS, Grunfeld EA, Ramirez AJ. Help-seeking intentions for breast-cancer symptoms: a comparison of the self-regulation model and the theory of planned behavior. Br J Health Psychol 2003; 8:319-33.

32. Nelson K, Geiger AM, Mangione CM. Effect of health beliefs on delays in care for abnormal cervical cytology in a multi-ethnic population. J Gen Intern Med 2002; 17:709-16.

33. van Balen F, Verdurmen J. Medical anxiety and the choice for treatment: the development of an instrument to measure fear of treatment. Psychol Health 1999; 14:927-35.

34. Malcolm CE, Cumming DC. Follow-up of infertile couples who dropped out of a specialist fertility clinic. Fertil Steril 2004; 81:269-70.

35. Callan VJ, Hennessey JF. The psychological adjustment of women experiencing infertility. Br J Med Psychol 1988; 61(Pt 2):137- 40.

36. Moore PJ, Sickel AE, Malat J, Williams D, Jackson J, Adier NE. Psychosocial factors in medical and psychological treatment avoidance: the role of the doctor-patient relationship. J Health Psychol 2004; 9:421-33.

37. Rose A, Peters N, Shea J, Armstrong K. Development and testing of the health care system distrust scale. J Gen Intern Med 2004; 19:57-63.

38. Bogart LM, Bird ST, Walt LC, Delahanty DL, Figler JL. Association of stereotypes about physicians to health care satisfaction, helpseeking behavior, and adherence to treatment. Soc Sci Med 2004; 58:1049-58.

39. van Ryn M, Burke J. The effect of patient race and socio-economic status on physicians' perceptions of patients. Soc Sci Med 2000; 50:813-28.

40. Chandra A, Stephen EH. Impaired fecundity in the United States 1982-1995. Fam Plann Perspect 1998; 30:34-42.

41. van Balen F, Verdurmen J, Ketting E. Choice and motivations of infertile couples. Patient Educ Counseling 1997; 31:19-27.

42. Jain T, Harlow BL, Hornstein MD. Insurance coverage and outcomes of in vitro fertilization. N Engl J Med 2002; 347:661-6.

43. DeNavas-Walt C, Proctor BD, Lee CH. Income, poverty, and health insurance coverage in the United States: 2004. Washington, DC: U.S. Government Printing Office, 2005.

44. Jain T, Hornstein MD. Disparities in access to infertility services in a state with mandated insurance coverage. Fertil Steril 2005; 84:221-3.

45. Gornick ME. Disparities in medical services: potential causes, plausible explanation, and recommendations. Health Care Financing Rev 2000; 21:23-43.

46. Thompson HS, Valdimarsdottir HB, Kinkel G, Jandorf L, Redd W. The group-based medical mistrust scale: psychometric properties and association with breast cancer screening. Prev Med 2004; 38:209-19.

47. Gurmankin A, Caplan A, Braverman A. Screening practices and belief of assisted reproductive technology programs. Fertil Steril 2005; 83:61-7,

48. Molock SD. Racial, cultural, and religious issues in infertility counseling. In: Burns LH, Covington SN, eds. Infertility counseling: a comprehensive handbook for clinicians. New York: Pantheon, 1999: 249-65. 